\title{
TENDENCIAS SOBRE EL DELITO DEL PROXENETISMO EN EL MARCO DE LAS REGULACIONES SOBRE EL TRABAJO SEXUAL: UN ANÁLISIS SOCIO JURÍDICO A PARTIR DEL RELATO DE MUJERES EN SITUACIÓN PROSTITUCIONAL DEL URUGUAY
}

\author{
Pablo Guerra ${ }^{1}$
}

\section{Resumen}

En este artículo analizaremos cómo se ha ido configurando la sensibilidad social en torno a las figuras delictivas del proxenetismo y cómo la misma ha ido variando conforme el paradigma de interpretación del fenómeno prostitucional con el que se mire este hecho. Partiendo de la situación actual en Uruguay, donde el trabajo sexual se encuentra regulado, sostendremos desde una óptica de sociología jurídica, que la figura delictiva del proxenetismo se encuentra en una fase interpretativa de transición, habida cuenta las dificultades para aplicar la norma en el actual contexto. En base a la evidencia empírica que resulta de una investigación de campo a 188 trabajadoras sexuales, advertimos sobre la conexión que puede existir entre indicios de relación de dependencia y figura de proxenetismo.

Palabras claves: prostitución, trabajo sexual, proxenetismo, género, derecho penal.

\section{INTRODUCCIÓN: LOS PARADIGMAS DOMINANTES EN EL DEBATE SOBRE LA PROSTITUCIÓN}

Numerosos actores sociales y públicos en las últimas décadas se han enfrentado a la hora de responder a la pregunta si el hecho social de la prostitución debe entenderse como un trabajo o como una expresión de explotación de género, reposicionando una vieja discusión que hace algo más de cien años dividía aguas entre prohibicionistas, abolicionistas y regulacionistas; o algunas discusiones más contemporáneas en el seno del feminismo, que dividía aguas - y divide- entre partidarios del feminismo radical (la prostitución es considerada como una expresión del patriarcado) y partidarios del feminismo liberal (la prostitución es vista desde el paradigma del empoderamiento y la agencia). Es así que las políticas públicas (y las legislaciones que le siguen) responden a un debate muy actual que se posiciona en el ámbito público a partir de los años 90 a raíz del

\footnotetext{
${ }^{1}$ Profesor e Investigador en Carrera de Relaciones Laborales, Facultad de Derecho, Universidad de la República (Montevideo Uruguay). Docente en Sociología del Trabajo y Economía Solidaria. Investigador Activo SNI. Autor de más de 20 libros y numerosos artículos publicados en revistas científicas de América y Europa. Ex Editor y actual integrante del Comité Editorial de la Revista de la Facultad de Derecho (Uruguay).E-mail: profguerra@yahoo.com.ar
} vol.08, nº. 02, Rio de Janeiro, 2015. pp. 735-757 
desarrollo que han tenido ciertos actores organizados de trabajadoras sexuales que reclaman sean consideradas trabajadoras y por lo tanto con acceso a todos los derechos laborales. También han contribuido a esta visión, la acción llevada adelante por ciertas esferas de la OMS y OIT partidarias de instalar una expresión más neutral para referirse a las personas que trabajan ofreciendo servicios sexuales, toda vez que términos como "meretriz" o "prostituta" son percibidos como despectivos. Una alta cuota de polarización vuelve a ponerse en escena cuando desde posiciones contrarias se defiende la idea que en los actuales contextos culturales, la prostitución es una actividad que esconde una relación de poder netamente machista y que en todos los casos remite más bien a un modelo de explotación sexual.

Es así que por un lado están quienes vienen insistiendo desde hace algún tiempo, que la prostitución presenta características que poco se diferencian de cualquier otro oficio y por lo tanto debiera regularse como trabajo. Así se expresan muchas activistas defensoras de la mirada de este fenómeno como trabajo sexual. Por ejemplo, una asociación de trabajadoras sexuales de España, afirma que:

Dentro de un marco de derechos y poder de decisión, las trabajadoras sexuales definimos a nuestra actividad como un trabajo, más allá de las eternas discusiones con grupos de moralistas, algunas organizaciones de mujeres que se ven estimuladas por un imperativo moral de salvar a mujeres inocentes (poniéndonos en el papel de víctimas y amputándonos el derecho de hablar por nosotras mismas)" (MILUSKA VIDA Y DIGNIDAD, 2006).

Por otro lado se ubican aquellos actores que analizando la forma en que opera la prostitución, el marco en que se desarrolla, y las consecuencias que acarrea, terminan sentenciando lo contrario, esto es, que la prostitución no puede ser considerada un trabajo como cualquier otro:

No puede ser considerado como un trabajo algo que implica y genera violencia, vejación, desprotección, desprecio y marginalización. Es una explotación. Es la traducción de una estructura social sexista y patriarcal. Es una forma de dominación del hombre sobre la mujer. Es la sumisión de la sexualidad del sexo femenino al masculino. Es un reflejo y un síntoma de la desigualdad entre los sexos" (MARTíNEZ, 2000).

Mientras que la primera cita la ubicamos en la corriente denominada "paradigma del empoderamiento" que enfatiza en la normalización del mercado sexual y apuesta a los beneficios que la regulación puede traer para quienes se dedican a esta actividad, la segunda cita es propia del "paradigma de la opresión" que pone énfasis en la naturaleza explotadora de este tipo de transacción.

En Uruguay, las políticas públicas adoptaron a partir de 2002 una lectura de la prostitución como trabajo. Resultado de este enfoque es la Ley 17.515 que define lacónicamente al trabajo sexual de la siguiente manera: "Son trabajadores sexuales todas las personas may, actores de dieciocho años de edad que habitualmente ejerzan la prostitución, recibiendo a cambio una remuneración en dinero o en especie” (URUGUAY: 2002). 
Al referirse a la mayoría de edad, niega la posibilidad de prostitución legal entre menores. Es así que el comité de erradicación de la explotación sexual infantil, ha promovido en los últimos años una lectura de la prostitución como explotación sexual, toda vez que sea ejercida por menores.

Otros aspectos importantes de esta definición es que habilita la condición de trabajador/a incluso con pagos en especies y sin explicitar la voluntad de ejercer la prostitución. Ambos elementos pretenden ser modificados por la Comisión Honoraria sobre Trabajo Sexual, que ha elaborado un ante proyecto para modificar la Ley (CHTS, 2014).

Un último aspecto deficitario de la definición legal adoptada en Uruguay, es que equipara la figura del trabajador/a sexual con quien se prostituye. Esta definición creemos no coincide con las definiciones generadas desde ámbitos académicos y que parten de la base que son trabajadores/as sexuales quienes se desempeñan en una amplia oferta del mercado sexual, incluyendo notoriamente a quienes se prostituyen, pero también a quienes se emplean en la industria pornográfica, como stripers, etc. (WEITZER, 2009).

La evidencia que mostraremos en este artículo ha sido recogida en el marco de la investigación titulada "Indagación sobre condiciones de trabajo y opinión sobre trata de personas entre población que ejerce la prostitución femenina en Uruguay". Uno de los objetivos de esta investigación es analizar el papel que el proxenetismo juega en el sistema prostitucional del Uruguay a partir de los relatos de las trabajadoras sexuales. En consonancia con este objetivo, se pretende analizar las eventuales conexiones de esta figura con la figura de la relación de dependencia. Partiremos en tal sentido de la hipótesis que en la medida en que las trabajadoras sexuales deban cumplir un horario fijado por un tercero y/o no tengan margen de libertad para atender clientes, entonces se configura una relación de dependencia que por sus particulares características nos aproximan a la figura del proxenetismo.

\section{MARCO CONCEPTUAL Y EVOLUCIÓN EN EL DEBATE SOBRE PROSTITUCIÓN Y PROXENETISMO}

El sentido y el alcance que la sociedad y la ley le han dado al proxenetismo han ido variando con el tiempo y no han estado exentos de polémicas. Sociológicamente, el término reviste connotaciones evidentemente negativas, asociándose inicialmente esta figura a la del explotador que persuade u obliga a una tercera persona a prostituirse obteniendo por ese medio un lucro que nunca gozó de la legitimidad que el mercantilismo permitía para otras áreas de intercambio comercial.

En la ilustración N. 1 exponemos a nuestro criterio cuáles han sido las grandes etapas en la modernidad en lo que respecta a la sensibilidad social respecto a prostitución y proxenetismo y cómo han ido impactando en las políticas públicas con legislación específica. 
Imagen 1: Mapa conceptual etapas de sensibilidad social frente al proxenetismo y prostitución

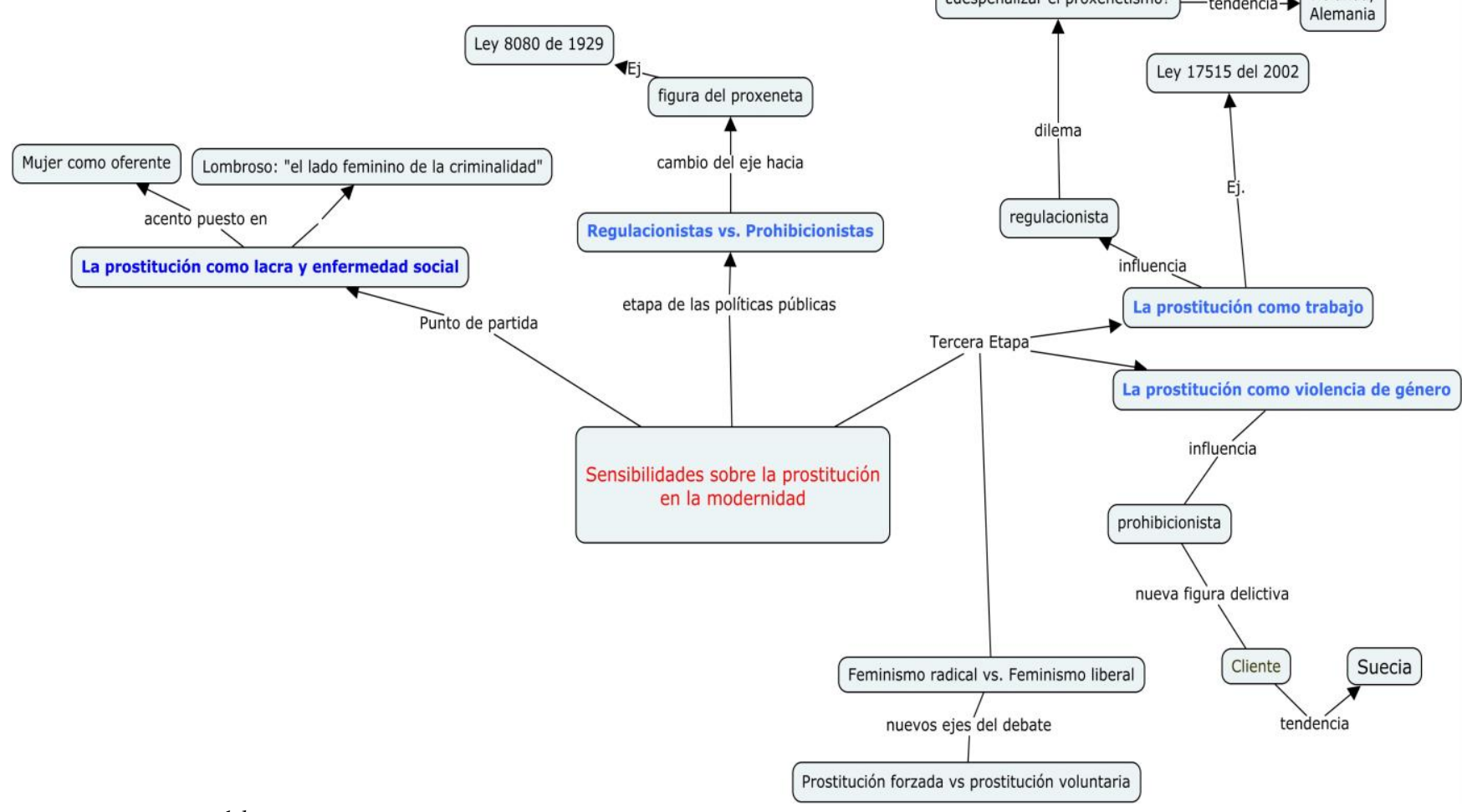

Fuente: elaboración propia

El pico máximo de exposición en el debate público sobre la figura del proxenetismo se da luego de superada una primera etapa donde la prostitución es vista como "enfermedad y lacra social". Esta primera etapa se caracteriza por poner su foco de análisis y condena en la mujer que se prostituye. Una segunda etapa (regulacionistas vs. Prohibicionistas y en menor medida abolicionistas), por su parte, va cambiando el enfoque y se desenvuelve en la segunda mitad del S. XIX en medio de la polémica sobre la "trata de blancas". Aquí el sujeto que se condena fundamentalmente es el del proxeneta, esto es, la persona que explota a una mujer con ánimo de lucro. Ilustremos con dos hitos del momento: por un lado, en 1863 el Parlamento británico sanciona una ley que castiga con látigo al proxeneta, desatando de esta manera una serie de legislaciones en la materia; por otra parte en 1899 tiene lugar en Londres, el primer congreso internacional sobre trata de blancas (TROCHÓN, 2006; LAZO, 2011) con activa participación de diferentes países de Europa además de Estados Unidos, inaugurando de esta manera un proceso de discusión internacional que luego continuaría en la Liga de las Naciones. Estos hechos obedecían a un intenso tráfico que tendría un epicentro de notoriedad en la región, a saber, con el desembarco en los puertos (fundamentalmente de Buenos Aires y Río de Janeiro para el sur del continente) de miles de mujeres traídas fundamentalmente desde Europa. Para hacerle frente se suceden convenios internacionales, como el celebrado en París en el año 1904 "Convenio para la Supresión de la Trata de Blancas" (la denominación "trata de 
personas" comienza a instalarse sobre mitad del S. XX) que tenía como propósito no solo proteger a las víctimas del tráfico, sino además reprimir a los agentes económicos intervinientes; o la Convención Internacional para la Supresión de la Trata de Blancas de 1910, donde por primera vez se establece una definición del delito de trata y proxenetismo (SOCIEDAD DE NACIONES, 1910) enfocado en el plano internacional. El documento internacional más paradigmático de esta fase es la Convención para la Represión de la Trata de Personas y de la explotación de la prostitución ajena (NACIONES UNIDAS, 1949), de cuño abolicionista que parte de una definición de prostitución como incompatible "con la dignidad y el valor de la persona humana" y en tal sentido conviene en castigar a quien explote la prostitución de otra persona o incluso "mantuviere" o "administrase" una casa de prostitución (NACIONES UNIDAS, 1949). Mientras tanto, esta especial sensibilidad contra el proxeneta (sobre cuyos antecedentes como delito nos podemos remontar a la antigüedad) se plasma notoriamente en el Código Penal Alemán de 1900 (Ley Heinze), además primer texto legal que establece la distinción entre el proxenetismo y el rufianismo (JIMÉNEZ DE ASÚA, 1950).

Incluso en países regulacionistas como el nuestro, la imagen de perversión de esta figura conduce al hecho de establecer la legalidad de la prostitución y de "casas de tolerancia" pero la ilegalidad de quien interviene en el negocio con fines de explotación y de lucro. Es así que se explica la Ley 5520 de octubre de 1916, que introduce el delito de proxenetismo, en el contexto de algunos cambios regionales relevantes (Argentina aprobaba la llamada Ley Palacios en 1913; en tanto Brasil comenzaba a expulsar proxenetas de su país en el marco de una campaña de "profilaxia social") que dispararon la presencia de este fenómeno en el país. Esta Ley, sin embargo, con el ánimo de no desarmonizar la reglamentación vigente, excluía del proxenetismo a quien regenteaba el prostíbulo, lo que no dejaba conforme a los abolicionistas, quienes dudaban acerca de su eficiencia si no se eliminaba toda reglamentación de la prostitución. Para entonces Paulina Luisi, figura señera del feminismo uruguayo, se preguntaría algo que casi 100 años después asoma especialmente pertinente para el debate y para el sentido de este artículo: ¿será posible eliminar el proxenetismo si se permite la existencia de personas encargada de regentear los prostíbulos? En la medida que subsistan las casas de tolerancia, esta Ley, decía, sería solo "una cataplasma aplicada sobre una pierna de palo" (TROCHÓN, 2006: 368). Esta figura del proxeneta, unida a la figura del rufián, y a la entonces denominada trata de blancas, constituía la tríada de "delitos y actos punibles en que la prostituta es sujeto paciente" (ALBANELL, 1932: 28).

La tercera etapa, finalmente, es la que instala en el seno de las políticas públicas la polémica entre partidarios de una regulación por la vía del "trabajo sexual" y partidarios de una mirada acorde con el paradigma de la opresión, sin desconocer aportes que evitan posturas dicotómicas, como sucede con Beatriz Gimeno cuando impulsa un "giro en el debate" entre el abolicionismo y regulacionismo (GIMENO, 2013). A diferencia de la etapa anterior, predomina aquí una intensa participación del feminismo y de la lectura de género (SCOTT, 1996) lo 
que -más allá de las diferencias entre radicales y liberales- permite superar la mirada condenatoria hacia la mujer. En todo caso, se inaugura en esta etapa el paradigma de intervención basado en la condena hacia la demanda, un elemento notoriamente ausente en las etapas anteriores, que comienza a plasmarse con fuerza en Suecia, desde los años ochenta (EKBERG, 2004: 14). El modelo sueco, plasmado en su Ley de Prohibición de compra de servicios sexuales (la denominada Sexköpslag de 1999) al entender la prostitución como una forma de violencia sexual masculina contra las mujeres y las niñas, condena al consumidor con penas de multas y prisión hasta seis meses (REGERINGKANSLIET, 2004:3).

La prostitución aquí no es vista como un trabajo, sino como una expresión patriarcal de opresión a la mujer, que hay que tratar de erradicar, por lo que se persigue al demandante (cliente). Las prostitutas, son consideradas víctimas, por lo tanto no sufren sanciones. Francia y Corea del Sur también exhiben modelos similares al sueco.

Sus críticos establecen que parte de una concepción de la prostituta como víctima, estableciéndose un modelo de razonamiento del tipo "prostitución pasiva" que no logra romper con el paradigma de la prostitución como un vicio social (JORDAN, 2012: 15-16).

El modelo que se le opone es el establecido en Alemania y Holanda (GELSTHORPE ET ALT, 2004: 286). En estos países, la prostitución es reconocida como un trabajo aún en locales y cuando la independencia laboral no es tan evidente. En Holanda, por ejemplo, una reforma del año 2000 elimina el delito de la explotación de la prostitución ajena, siempre y cuando el trabajo sexual sea voluntario. Desde entonces no solo que la prostitución no forzada de un adulto pasó a ser lícita y considerada una actividad laboral, sino que además, los prostíbulos pasaron a considerarse como un negocio más, algo que se puede observar hoy recorriendo el famoso "barrio rojo" de Amsterdam, donde las trabajadoras se exhiben en las vitrinas de los locales.

Para el caso de Alemania, la actual legislación también considera a la prostitución como una actividad lícita, posibilitando la existencia de una relación laboral aunque con algunos límites específicos en la subordinación patronal. En concreto, la reforma de 2002 permite a los dueños de burdeles no ser considerados proxenetas, en la medida que intermedien entre la demanda y una oferta de carácter netamente voluntaria, que desde entonces debe aportar a la seguridad social.

\section{LEGISLACIÓN ACTUAL SOBRE PROXENETISMO Y PROSTITUCIÓN EN URUGUAY}

Actualmente el proxenetismo está tipificado como delito, de acuerdo al Código Penal en su Artículo 274, que remite a la Ley 8080 del año 1927. En este texto legal se define al proxeneta como "Toda persona de uno u otro sexo, que explote la prostitución de otra contribuyendo a ello en cualquier forma con ánimo de lucro, aunque 
haya mediado el consentimiento de la víctima..." (URUGUAY, 1927). La Ley 16707 incorpora un segundo inciso, a saber: "El que, con ánimo de lucro, indujere o determinare a otro al ejercicio de la prostitución, en el país o en el extranjero, será castigado con tres a doce meses de prisión" (URUGUAY, 1995). En su momento, esta Ley fue considerada más represiva que la de 1916 en tanto se establecía que caía en proxenetismo quien "en cualquier forma" "contribuyera” a la explotación de la víctima. Recordemos que la Ley de 1916 no castigaba al regente del prostíbulo, situación que se corrige con la nueva legislación. Dice al respecto Albanell: "La ley 8080 se caracteriza ante todo, por la voluntad de suprimir una forma activa del proxenetismo que había dejado inmune la ley 5520: el realizado por la persona regente de una casa de prostitución” (ALBANELL, 1932: 62). Digamos además, que la elección del verbo "contribuir" fue elegido en vez del verbo "promover" que circulaba en versiones anteriores manejadas por la Comisión Parlamentaria, en una señal evidente de pretender la mayor amplitud posible en el delito de proxenetismo.

La misma sociedad, sin embargo, con el paso del tiempo parece ir naturalizando el hecho que para dar cumplimiento a la prostitución como un derecho, se vayan desarrollando negocios legales y reglamentados donde evidentemente existen actores económicos que sacan cuantiosos provechos mercantiles. Mientras ello ocurre, los valores a proteger (que el Derecho Penal reconoce como "el bien jurídico" que se protege) parecen ir desde una genérica defensa de la moral y buenas costumbres, a la defensa de la libertad sexual. Dicho de otra manera, mientras que en una etapa fundacional del delito el proxeneta era visto como el principal causante de la prostitución y ésta era vista como un mal que era deseable erradicar, con el correr del tiempo el proxeneta pasó a ser visto como el violador al derecho que toda persona tiene de decidir sobre su cuerpo y sexualidad, lo que implica además, derecho a gozar de los beneficios económicos generados por su trabajo, en caso de trabajar en el negocio del sexo.

A nuestro entender, en la actualidad el problema se suscita a la hora de interpretar el alcance de la mencionada "explotación". En tal sentido, exponemos lo que a nuestro criterio son las tres principales interpretaciones:

1. Explotación en el sentido económico. En términos económicos, suele utilizarse la expresión "explotación" como sinónimo de "hacer rendir" económicamente alguna actividad (p.e. "explotar" un negocio) o factor productivo. Esta idea es la que recoge la Real Academia Española en la segunda acepción que le da a nuestro término: "Sacar utilidad de un negocio o industria en provecho propio" (REAL ACADEMIA ESPAÑOLA, 2001). Se desprende de esta interpretación que buena parte de los actores vinculados al negocio de la prostitución reglamentada están participando como proxenetas, pues en los hechos su inserción en el mercado de la prostitución les permite sacar un provecho en beneficio propio de las personas que ejercen la prostitución. Esta interpretación es la que primó entre los 
legisladores de la Ley de 1927, que como señalamos antes, buscaban explícitamente -así lo expusieron en la exposición de motivos- incluir a aquellas personas que regenteaban los prostíbulos, no alcanzados por la norma de 1916.

2. Explotación en el sentido abusivo del término. Una segunda interpretación es entender a la explotación en un sentido abusivo del término. Este es el caso, por ejemplo, de la explotación laboral bajo el paradigma marxista, en el sentido que el capitalista se queda con el plusvalor generado por el trabajo y no pagado por el propietario de los medios de producción. Bajo esta mirada, que a nuestro entender presenta componentes subjetivos, habría que demostrar que hay un abuso de una persona hacia otra (en este caso una trabajadora sexual) en provecho del primero. A los efectos de objetivar el abuso, se podría establecer un rango de lo que implica una relación laboral "no explotadora", como es el caso de objetivar determinado ingreso, determinadas condiciones laborales, horas de trabajo, etc.

3. Explotación con aplicación en el negocio y no en la persona. Una tercera interpretación posible intenta distinguir entre la explotación a la persona y la explotación del negocio. Esta distinción creemos es algo tortuosa, pero ha sido defendida por aquellos juristas que entienden imposible legalizar el negocio de la prostitución si no se distingue la explotación de una persona de la explotación, por ejemplo, de un establecimiento o local donde trabajen esas personas. Nótese que la Ley que regula el trabajo sexual en Uruguay, establece en su Artículo 4 que "Las tareas de prevención y represión de la explotación de las personas que ejerzan el trabajo sexual, así como el evitar perjuicio a terceros y preservar el orden público, serán competencia del Ministerio del Interior" (URUGUAY, 2002) (subrayado nuestro). El legislador parece inclinarse en este último sentido, es decir, distinguir la explotación de las personas de la explotación del negocio. Esta interpretación creemos es algo tortuosa pues resulta muy complejo diferenciar el negocio del principal factor productivo del negocio (en este caso el trabajo sexual). Parecería ser una salida sin mayores argumentos doctrinarios para justificar la evidente presencia de empresarios que lucran en el rubro. En todo caso, la recurrencia a la "explotación de las personas" en vez de "explotación de la prostitución" debería incorporar algún baremo.

Creemos que en la búsqueda de indicadores más o menos precisos que podamos utilizar para diferenciar la explotación de las personas de la explotación del negocio de la prostitución le cabe un rol importante a la posible relación de dependencia que exista entre la trabajadora sexual y el empresario del rubro. Bajo esta mirada, podríamos incluir en un extremo cierta prostitución autónoma. Aquí, la trabajadora define por ejemplo, sus tiempos de trabajo, sus ritmos de trabajo, las condiciones en las que realizará el trabajo y las tarifas aplicar. En el otro extremo podríamos ubicar la relación de dependencia. Aquí, la trabajadora tiene que aceptar los tiempos de trabajo que le imponga su empleador, los ritmos de trabajo, ciertas condiciones específicas y las tarifas a aplicar. 
Visto del lado del empresario, participaría del negocio bajo situación de autonomía si no interviene en las definiciones de las dimensiones señaladas antes, en tanto participa de la relación de dependencia en carácter de patrón si define alguna de esas dimensiones.

Esta postura es defendida por ciertos analistas más proclives a las tesis regulacionistas antes que prohibicionistas. Por ejemplo, Martha Solis se distancia de las tesis que ven una situación de semiesclavitud en toda relación prostituta - prostituyente, ya que esta relación solo es posible advertir cuando un empleador abusa de su empleado, no siendo el caso -dice- respecto a lo que ocurre normalmente en la relación cliente - prostituta:

El cliente no es un empleador sino un consumidor y la relación que surge entre ellos, está limitada por el tiempo y el espacio. Donde el consentimiento siempre está siendo negociado y sólo cuando esa capacidad de negociación se encuentra mermada -porque otra persona tiene la potestad para decidir cuántos clientes ha de tomar, qué servicios realizar- o su consentimiento es anulado, podemos decir que estamos ante un caso de esclavitud" (SOLIS, 2011: 132).

En esta frase podemos observar cómo la autora parece desmarcarse de la idea que asimila a la prostitución con el trabajo esclavo en la medida que exista negociación entre las partes. Sin embargo admite la posibilidad que otras personas intervengan para mermar el consentimiento o grados de autonomía de la trabajadora. Cuando eso ocurre, dice, estaríamos en presencia de esclavitud. Siguiendo este razonamiento, bastaría entonces advertir que en algunos aspectos quienes se prostituyen no tienen margen de decisión para apartarnos del paradigma del trabajo y acercarnos al paradigma de la explotación. Nuestra investigación, adelantamos, expone esas limitaciones.

En esta línea, algunos juristas se han inclinado por considerar a la prostitución una actividad económica lícita, al menos en su variante como trabajo independiente. Es el caso de la sentencia C-268/99 del Tribunal de Justicia de las Comunidades Europeas, que ha sido especialmente estudiada como pieza de jurisprudencia al evitar una mirada de la prostitución como desviación y haber introducido la posibilidad de considerarla una actividad económica lícita.

\section{METODOLOGÍA Y RECORTE OPERACIONAL}

En los meses de Junio y Julio de 2014 se realizaron 188 entrevistas en profundidad semiestructuradas, aplicadas a trabajadoras sexuales. La muestra es estadísticamente representativa con un margen de confianza del 95\% y límite aceptable de error muestral de 7.3\%

Para el cálculo del tamaño de la muestra se utilizó la siguiente fórmula: 


$$
n=\frac{N \sigma^{2} Z^{2}}{(N-1) e^{2}+\sigma^{2} Z^{2}}
$$

Donde:

$\mathrm{n}=$ el tamaño de la muestra.

$\mathrm{N}$ = tamaño de la población.

Desviación estándar de la población (valor 0,5 ).

$\mathrm{Z}=$ Tomado en relación al $95 \%$ de confianza equivalente a 1,96 .

e = Límite aceptable de error muestral del 7.3\%

Se partió de un $\mathrm{N}$ tentativo de 10.000 casos. Ese número responde a un estimativo teniendo en cuenta que existen actualmente 11.157 mujeres inscriptas en el Registro Nacional de Trabajo Sexual gestionado por el Ministerio del Interior y que ese número no contempla las bajas que naturalmente se dan con el paso del tiempo; en tanto los datos de las personas que en el último año han pasado por Policlínicas del Ministerio de Salud Pública para tener su carné de salud apto para trabajar, asciende a 3.660 mujeres.

La pauta de entrevista fue elaborada a los efectos de conocer las condiciones de trabajo de quienes ejercen la prostitución, así como la opinión sobre diversos tópicos. La ejecución de esa pauta correspondió a estudiantes del curso de Sociología del Trabajo de la Licenciatura en Relaciones Laborales (Facultad de Derecho Universidad de la República).

Las entrevistas fueron realizadas mayormente en Montevideo a una muestra de carácter aleatoria de trabajadoras sexuales mediante estrategia de dispersión para establecer contactos en variadas fuentes prostitucionales previamente establecidas. A los efectos de esta investigación se entenderá como trabajadora sexual a toda mujer que tenga como principal ingreso económico las retribuciones monetarias obtenidas a cambio de realizar cualquier tipo de servicio sexual directo. Quedaron excluidas de la muestra aquellas personas que ocasionalmente se prostituyen.

A los efectos de obtener información sobre los distintos tipos de prostitución, se procuró indagar sobre los siguientes campos específicos: prostitución de la calle, prostitución en locales específicos (burdeles, casas de masajes, whiskerías) y otras vías de prostitución (catálogo, Internet, avisos clasificados, call girls, etc.).

En este artículo haremos referencia a los resultados en torno a dos de las variables estudiadas, esto es, "presencia de proxenetismo" y "presencia de relación de dependencia", siendo que esta última ha dado lugar a otras variables posteriores. 


\section{ANÁLISIS DE LA INFORMACIÓN}

Respecto a la eventual figura de terceros que manejen el negocio de la prostitución bajo figuras como el proxenetismo (fiolo o cafisho en la jerga popular, también es de uso la antigua expresión policial "840"), nuestra investigación indaga mediante una pregunta concreta así como otras preguntas que pretenden llegar a esta eventual figura por otras vías. La pregunta principal es: “¿Tenés o tuviste algún tipo de intermediario o persona del ambiente que pretendiera o pretenda quedarse con una parte de lo que ganas?" Es de destacar que esta pregunta tiene como propósito aproximarse a la figura del proxeneta como sujeto que coacciona a otra para prostituirla. Por lo tanto la pregunta que realizamos es solo una puerta de entrada para obtener información en la materia y fue complementada con otras preguntas posteriores que tenían como propósito seguir indagando sobre la posible existencia de alguna persona que obligara a las entrevistadas a prostituirse. Ha habido en ese sentido, un esfuerzo de crítica codificación en el análisis de las respuestas, pues en algunos casos las respuestas se confundían con la figura de quien administra, regentea o dirige los locales (mayormente mujeres en el caso de casas de masajes y prostíbulos; mayormente varones en el caso de whiskerías).

En ese caso, la mera presencia de personas que por su posición en el negocio se quedan con un margen del precio final (ya sea por el costo de la habitación u otros costos del proceso de trabajo) a los efectos de esta investigación no es condición suficiente como para configurar presencia de proxenetismo. Otras veces podía llegar a confundirse con los servicios informales de vigilancia contratados por quienes hacen calle. En ese sentido, tampoco entendemos que configure proxenetismo, salvo que luego comprobemos por las otras preguntas que hay cierta relación de dependencia con esos sujetos:

- Toda la platita es para mí (NdeR: señala su cartera) y le tiro unos pesos al negro quien es quien nos cuida.

- ¿Quién es el negro?

- Es el chabón que recorre la zona y nos cuida y vigila que no pase nada (E97).

En tal sentido, se estableció una definición operativa conservadora para establecer la presencia de proxenetismo, a saber:

CPP (Categoría Presencia Proxenetismo). Una entrevistada integra la categoría "Presencia de Proxenetismo" cuando:

1. exprese directamente que vivió situaciones de proxenetismo;

2. exprese directamente que en algún momento tuvo "fiolos" "cafishos" o una figura cercana que le exigía prostituirse y le retenía el total o parte de sus ganancias;

3. mencione la presencia de figuras cercanas que le exigían prostituirse en algún momento de su trayectoria;

4. comente en algún momento de la entrevista que no puede dar determinada información porque alguna persona de su entorno le puede agredir 
CSEP (Categoría sin evidencia de proxenetismo). Una entrevistada integra la categoría "Sin evidencia de Proxenetismo" cuando sus respuestas no integren la CPP, por ejemplo:

1. exprese directamente que no ha tenido nunca situaciones de proxenetismo;

2. exprese directamente que no permitió ni permitiría que nadie se quedara con el fruto de su trabajo;

3. responda negativamente sobre presencia de figuras aproximadas al proxenetismo.

Por fuera de esa pregunta disparadora sobre el tema trabajaremos otras dos que tienen como objetivo testear la posibilidad que exista alguna figura que controle el trabajo sexual de las entrevistadas, a saber:

$$
\begin{gathered}
\text { 7. ¿Y alguna persona te exige cumplir un determinado } \\
\text { horario o eso lo decides tú? }
\end{gathered}
$$

Estas dos preguntas indagan sobre posibilidad de relación de dependencia, pero en determinadas condiciones creemos pueden exponer situaciones de proxenetismo. Los valores asignados a las respuestas en el caso de la P7 son: 1: SI, 2: NO, 9: NS/NC. En el caso de la P8 son: 1: Manifiesta tener margen para decidir; 2: Manifiesta no tener margen para decidir por presión de un tercero; 3: Manifiesta atender siempre por razones intrínsecas a su trabajo; 9: NS/NC.

Debemos destacar que el cruce entre prostitución callejera y respuesta afirmativa en la pregunta 7 podría estar implicando la existencia de proxenetismo. La respuesta afirmativa en esta pregunta cuando el trabajo se realiza en locales cerrados, sin embargo, no implica necesariamente la existencia de un proxeneta, pues como veremos más adelante, el sistema de trabajo en estos locales establece el cumplimiento de un horario que se negocia o establece entre las partes. No obstante esto podría estar configurando una aproximación a un trabajo en relación de dependencia, y por esa vía acercarse a la figura del explotador al menos en la primera acepción que le hemos dado al término. En la calle, sin embargo, el trabajo autónomo implica que cada una decide la cantidad de horas que va a trabajar. Si hace mucho frío o llueve, por ejemplo, bajo condición de autonomía pueden tomar la decisión de retirarse. Lo mismo cuando la persona entrevistada entiende que ha ganado suficiente dinero: bajo condición de autonomía puede tomar la decisión de retirarse antes de lo previsto. Si de todas maneras deben continuar en la calle muy probablemente se deba a que una tercera figura le está controlando y vigilando.

No ocurre lo mismo con la pregunta 8 del formulario. Para esta consulta, cualquiera sea la forma de prostitución, el hecho de que se obligue a una trabajadora sexual a ofrecer sus servicios cuando por determinada razón no quiera hacerlo (valor 2), podría estar configurando la existencia de una figura explotadora. Obviamente que esta pregunta no refiere a la posibilidad de elegir el cliente (es el cliente el que elige), sino a la posibilidad de negarse por razones fundadas. La hipótesis que está detrás de esta pregunta es que bajo condición de autonomía 
(nos referimos a autonomía laboral) la trabajadora sexual tiene un margen de libertad que aplica mediante diversas estrategias para negarse a atender un cliente indeseado. Si no existe ningún margen de libertad entonces además de relación de dependencia podríamos estar en presencia de alguna figura explotadora.

Según se desprende del Cuadro 1, la mayoría establece no haber tenido una persona que se aproximara a la figura del proxeneta $(77,1 \%)$, pero como se dijo antes, la información cuantitativa aquí no es del todo confiable por dos razones: (a) probablemente la población que rechazó ser entrevistada presente una mayor tasa de proxenetismo; (b) algunas entrevistadas pudieron haber mentido en esta pregunta a los efectos de no padecer represiones. Eso significa que a nuestro entender la cifra aquí manejada es conservadora por las razones expuestas: $21,8 \%$ de la muestra integra la "categoría presencia de proxenetismo"

Cuadro 1: presencia inicial de proxenetismo

\begin{tabular}{|c|c|c|c|c|c|}
\hline & & Frequency & Percent & Valid Percent & Cumulative Percent \\
\hline \multirow{4}{*}{ Valid } & СPP & 41 & 21,8 & 21,8 & 21,8 \\
\hline & CSEP & 145 & 77,1 & 77,1 & 98,9 \\
\hline & $\mathrm{NS} / \mathrm{NC}$ & 2 & 1,1 & 1,1 & 100,0 \\
\hline & Total & 188 & 100,0 & 100,0 & \\
\hline
\end{tabular}

Fuente: elaboración propia

De acuerdo a la información recogida, tenemos que no hay evidencia inicial de proxenetismo en el $77.1 \%$ de los casos, en tanto sí hay presencia de proxenetismo en el $21,8 \%$ de la muestra.

Estos datos coinciden con la investigación de Guerra (GUERRA, 2004) donde se refiere a la hipótesis de un paulatino alejamiento de la figura clásica del proxeneta entre población prostituida más informada y autónoma. Es así que una parte importante de la muestra es enfática en cuanto a no aceptar que otra persona les presione para prostituirse y se quede con una parte del dinero obtenido:

- No no, fiolo jamás. No mija, me gusta mucho la plata como para que alguien me la venga a sacar. Al contrario, hasta ahora, vieja y todo aun no he perdido las mañas"(E35)

Por suerte no soy como esas minas que las maneja el marido que si no le da toda la plata la revientan, yo soy sola como dicen los viejos iviste? Pero mejor que mal acompañada, jseguro! (E36)

Como se puede observar, en este tipo de respuestas hay un cierto componente de Rational Choice que analizados desde una perspectiva de individualismo metodológico podría indicarnos que el proxenetismo, finalmente, no es más que una opción irracional. Evidentemente, como se verá luego, otros relatos nos mostrarán cómo el proxenetismo es una institución social propia de una cultura patriarcal cuyo peso no deja margen para eventuales decisiones libres y racionales por parte de las involucradas. 
En tal sentido, algo más de una de cada cinco entrevistadas, manifiestan haber tenido o tener una figura explotadora. En algunos, el proxenetismo refiere a casos de trata de personas con fines de explotación sexual fuera del país. Aunque este tema no será abordado en este artículo, digamos que en nuestra investigación surgieron algunos relatos en lo que se muestra la peor versión del proxenetismo:

El trabajo no fue lo que me habían dicho, me tuvieron encerrada un mes al oscuro, en una pieza chica, venían una vez por día a darme de comer, me drogaban. Me violaron y golpearon reiteradas veces. Me dijeron que mi vida podía cambiar y que podía ganar dinero y me sacarían del cuarto solo si yo aceptaba prostituirme. Era lo mismo que me hacían solo que ganaría dinero. Bueno, ta, ya sabes, me comencé a prostituir, a drogarme. Un día logre escapar del control al que me tenían sujeta. Fui a la policía y me "repatriaron" (E81).

Otros casos refieren a la situación local:

Antes tenía un fiolo, que la verdad era un hijo de puta, me cagaba a palos, me sacaba la guita hasta que un día no aguanté más. Le hice frente, me quería mandar a changar aunque estuviera menstruando le dije que no quería, me mandó igual, me siguió yo justo estaba con un cliente se acercó, el cliente se fue el me saco la plata que quiso lastimar con un cuchillo me cortó la panza, y ese día me fui a la comisaría y lo denuncié fui al juzgado a declarar y lo procesaron por lesiones graves con prisión, " menos mal" (E5).

No, ahora intermediarios no tengo, pero los tuve, tuve intermediarios mucho tiempo, generalmente cuando empezás tenés intermediarios porque sola es muy difícil, tenés que tener a alguien que te enseñe, que te guíe, que te dirija, porque después cuando en esto ya estás estabilizada de saber como manejarte y juntar plata, porque en el apartamento y más para laburar es difícil. (E28).

Una vez me enganche con un tipo que me dijo que me cuidaba y yo le daba algo, pero después se le fue la moto y me pedía mas, ahí se pudrió todo, resulta que aunque no hiciera nada igual tenía que pagarle, hasta me mando algunos viajes, pero yo le di también, de ahí nunca más, le dije que si quería plata abriera el las gambas (E77).

Ha surgido de la investigación, evidencia de proxenetismo vinculado y gatillado por el consumo de drogas. En este caso, además, se vuelve a poner en escena la posición dominante y explotadora del varón, que recurre a la estrategia del engaño y manipulación para someter luego a su víctima:

Yo estaba fumando, se me acabo, él se hacia el bueno, me daba más pasta base, más pasta base, más pasta base, me invito a ir a la casa y yo dije con éste que me da pasta base a cada rato me voy corriendo y agarre mis cosas corriendo y me fui pasando Colón, Complejo América, en el culo del mundo, y ta. Después que se terminó la pasta base me dijo: bueno, ahora tenes que salir a reponerla, salir a reponer lo que te fumaste. $Y$ de repente se quedaba con más plata de la que yo había fumado / ... / Una vez creo que traje ochocientos pesos y me dio una cachetada que me dejó mirando para atrás porque me faltaban doscientos pesos. (E171). 
En algunos casos esas figuras responden al entorno familiar, matizando entre la figura del proxeneta y la del rufián o cafisho:"En su momento sí. Como te dije, mi padre, mi tío, luego mis hombres, jaja. Pero hace años soy mi propia empresaria."(E54)

Nótese cómo en este relato, se explicitan bajo la fórmula del padre, tío y "mis hombres" los roles que comúnmente asume el patriarcalismo en las relaciones jerárquicas y de dominio sobre la mujer. "Si, el padre de mi segundo hijo. Yo salía a trabajar y él no hacia nada, me esperaba y me sacaba toda la plata todavía" (E58). "Te enamoran para después meterte a trabajar para ellos. Yo en generar no los considero, no los tomo mucho en cuenta; porque como me daba cuenta a tiempo. Pero cuando no sos muy avispada y te agarran, te ponen a trabajar para ellos, te fiolean" (E102).

También las figuras maternales contribuyen a sostener el ciclo de la explotación sexual: "Sí tuve que decidir o hasta a veces dejar todas mis ganancias a mi madre, pero yo no me daba cuenta que me estaba fiolando. Eso era cuando niña, cuando me explotaban" (E63)

En otros casos, las respuestas son negativas, pero los relatos manifiestan posturas cercanas a la figura del proxenetismo entre figuras del ámbito familiar: "Lo más cercano a un fiolo que tuve fue mi madre. Que lo que pasa es que también mi madre fue trabajadora sexual, mi abuela fue una mujer explotada” (E12).

También hay casos donde no se concreta la figura de proxenetismo, aunque estén presentes en algunos relatos ciertas figuras que se le aproximan aunque no lleguen a concretarse: "Hasta los fiolos mas grandes de Montevideo los tuve, todos ahí presentes. No me importaba facha, auto, nada, yo siempre tuve ese criterio, de que todo lo hacía por mis hijos (E130)". " No, he tenido la propuesta de trabajar para alguien si, pero no, yo trabajo para mis hijos...(E141)

Como puede apreciarse en estas respuestas, los hijos aparecen como legitimadores ya no del trabajo sexual, sino además de la renuncia a estar bajo la tutela de alguna figura explotadora. Como explica otra de nuestras entrevistadas: "Noo, yo trabajo para mi y mis hijos nadie me toca la guita... (E142)"

Otros casos donde se observa presencia de proxenetismo en el ambiente aunque no fueron concretadas por parte de nuestras entrevistadas. En algunos es estos relatos es evidente que la cercanía del fenómeno vuelve más vulnerable la propuesta autónoma que valoran nuestras entrevistadas: "No lo tuve, pero sí hubo un intento de un dueño de un boliche, al que yo concurría en Punta del Este y sabía que yo conocía clientes "exclusivos". Y me pidió que le empezara a dejar una comisión, a lo que no accedî" (E19)."Y si, acá hay de todo, ¿viste? Siempre alguien quiere aventajar, pero una no afloja y más o menos la vas llevando" (E45)

Mira ... se me acercaron una vez como a ofrecerme pero no accedí. No sé si estoy como para que me fijen condiciones. Prefiero seguir trabajando así y ser independiente y fijarme yo las condiciones: las personas que quiero, el horario que quiero y el precio que quiero. (E106). 
Nunca tuve intermediario. Nunca tuve porque me tocó ver a muchas compañeras, a muchísimas compañeras, cómo fueron explotadas a lo largo de su vida. Y cuando llegan a la vejez no tienen ni un acolchado donde caerse muerta porque todo lo han hecho para los fiolos. Todo por los fiolos. Yo no. (E136).

La opinión mayoritaria en la muestra que hemos analizado parece coincidir en que el proxenetismo es una expresión de dominio inaceptable. Si bien es evidente que esta figura tiene ondas raíces en las estructuras de dominio de género y se presenta como una de las peores expresiones de esclavitud contemporánea, se evidencia en los relatos, como dijimos antes, una suerte de análisis individualista del fenómeno, de tal manera que algunas de nuestras entrevistadas se apoyan en un discurso del tipo "el proxenetismo se puede evitar", no logrando comprender o justificar cómo algunas de sus colegas terminan explotadas por "sus hombres" o "sus maridos". Es así que en varios de los casos, se apunta directamente a la supuesta propia debilidad de quien -ejerciendo la prostitución- acepta que alguien más le exija prostituirse para luego sacarle todo o parte del dinero ganado, ignorando cómo estos comportamientos están notoriamente afectados por las pautas culturales dominantes:

No, yo soy muy viva en ese sentido, nono... la veo muy difícil, conozco gente sumisa, o sea, que ta... Pero yo tengo otra escuela, tengo otra enseñanza, como que estoy más avivada en ese sentido, no me lleva la plata nadie... Pero digo, es difícil, es difícil si, porque hay mujeres sumisas y zcómo te puedo decir? las enamoran y después le sacan hasta las ganas de vivir. (E118).

\section{¿RELACIÓN DE DEPENDENCIA EN EL TRABAJO SEXUAL?}

Esta dimensión de análisis, como dijimos fue medida por dos variables: cumplimiento de horarios y margen de libertad para negarse a atender clientes.

Respecto a la primera variable, como se desprende del cuadro 2, la muestra está dividida entre quienes manifiestan cumplir un horario y quienes no lo hacen.

Cuadro 2: exigencia cumplimiento horario

\begin{tabular}{|cc|c|c|c|c|}
\hline & Frequency & Percent & Valid Percent & Cumulative Percent \\
\hline \multirow{4}{*}{ Valid } & SI & 93 & 49,5 & 49,5 & 49,5 \\
& NO & 92 & 48,9 & 48,9 & 98,4 \\
& NS/NC & 3 & 1,6 & 1,6 & 100,0 \\
\cline { 2 - 6 } & Total & 188 & 100,0 & 100,0 & \\
\hline
\end{tabular}

Fuente: elaboración propia

Una respuesta típica entre los que señalan que sí deben mantener un horario es la que por ejemplo, expresa nuestra entrevistada en el siguiente pasaje:

Hay que cumplir un horario obviamente, porque es un trabajo, entonces tengo que hacer ocho horas. Yo por ejemplo, hago de ocho a cuatro pero a veces me voy antes, pasa que no tienen muchas cosas para decirme porque si vol.08, nº. 02, Rio de Janeiro, 2015. pp. 735-757 
me voy antes la que se jode soy yo, porque yo estoy acá ganando según los clientes que haya, si estoy cuatro horas y se me antoja irme me van a decir que me tengo que quedar porque no cumplo con el horario pero tampoco me muero si me echan porque la plata acá depende de mi, no es un sueldo fijo. (E104).

Cruzando la información por tipo de prostitución, encontramos que los lugares donde el cumplimiento de horario es la norma, son casas de masajes (92\%) y whiskerías (78\%), descendiendo notoriamente entre quienes trabajan en prostíbulos (33\%), call girls (13\%) y calle (11\%). Ese dato es consistente con la idea que el trabajo en whiskerías y casas de masajes se asemeja a una relación de dependencia, en tanto locales cerrados como prostíbulos manejan un sistema más autónomo que obviamente también se traduce en el trabajo de calle y en el sistema de call girls.

Incluso surge de muchos testimonios que la relación de dependencia llega hasta el punto de sancionar con multas a quienes falten o lleguen tarde a su trabajo:

Sí cuando estaba en locales sí. Es más, se nos obligaba a estar en los locales, se nos multaba. Se nos cobraban multas exorbitantes por llegar tarde a trabajar. Por ejemplo los días de votaciones no podemos faltar. Tenemos que trabajar sí o sí. No nos preguntan si tenemos cambio de credencial o si la credencial es de otro departamento. Ese día es el que más se trabaja. (E136)

$\mathrm{Si}$, en las whiskerías cuando estas en los locales te obligan a cumplir horario, te sancionan o te multan a la hora que faltas, como por llegar tarde o por demorar realizando tu trabajo en la pieza, aunque a la pieza te la cobran ¿no?"(E150)

Lo tengo que cumplir porque si no te multan o te sancionan. Como cualquier otro trabajo. Para ellos es, digamos, vos sos una meretriz pero, sí o sí, para ellos es como cualquier otro trabajo. Tenés que cumplir un horario, no podes faltar. Si faltas, tenés que llevar certificado. Es como cualquier otro trabajo. (E157)

En otros casos, no hay sistemas de multas pero se compele a las trabajadoras a cumplir con el horario:"Sí, esto es como cualquier trabajo, tenemos horario de entrada y horario de salida. No somos multada, como en otras casas de masajes viste, pero..." (E160). " Sí, tenés un horario como en cualquier trabajo normal. Tenés un horario,tenés reglas y cosas que cumplir. Tengo días libres y licencia, depende de cuánto tiempo haga, pero se puede arreglar..." (E178)

Como se puede observar, las propias entrevistadas expresan que el suyo es un trabajo como cualquier otro, en obvia referencia a cualquier trabajo asalariado y en relación de dependencia donde se debe cumplir con un horario.

En cuanto al cumplimiento de horario en la calle, situación que refiere a casi el 11\% de quienes se prostituyen en la vía pública, decíamos que podría traducirse en una eventual presencia de proxenetismo. De todas maneras, claramente esa no es una situación que pudiera generalizarse ya que muchas de quienes realizan sus tareas en la vía pública, cumplen un horario a los efectos de "cuidar su esquina", fenómeno que ocurre vol.08, nº. 02, Rio de Janeiro, 2015. pp. 735-757 
fundamentalmente cuando logran afincarse en un territorio especialmente atractivo para el encuentro entre la oferta y demanda.

Respecto a la posibilidad de negarse a atender algún cliente, una importante mayoría de la muestra señala que tiene algún margen para hacerlo, ya sea por razones sustantivas $(82,4 \%)$ o ya sea esgrimiendo razones profesionales $(9,6 \%)$ :

Cuadro 3: margen atención cliente

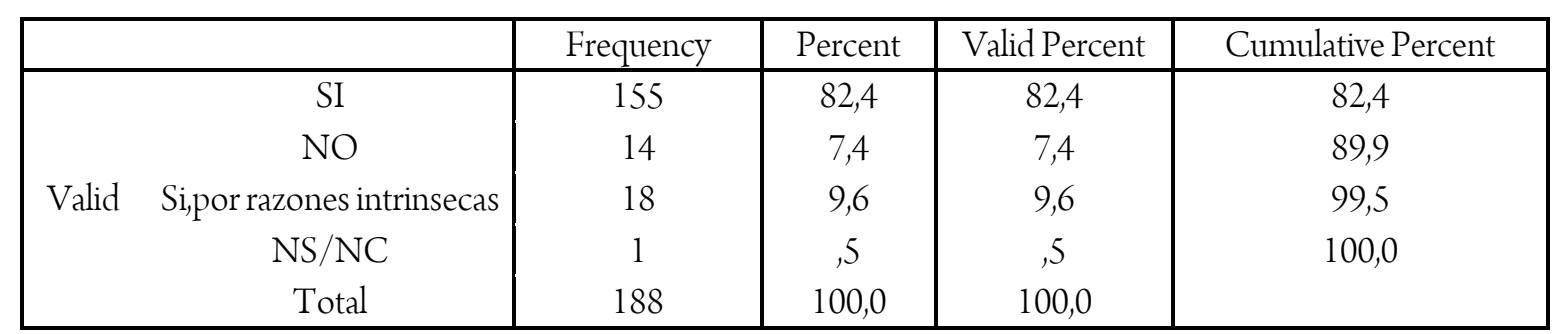

Fuente: elaboración propia

Corresponde detenerse, por lo tanto, en quienes señalan que no tienen margen para definir si atienden o no a algún cliente. La mitad de quienes no tienen margen, trabajan en whiskerías, y una cuarta parte lo hace en casas de masajes. Nuevamente aquí observamos cómo estos dos lugares exponen un modelo de negocios con escasa autonomía de trabajo por parte de quienes ejercen la prostitución."En la whiskeria que estaba antes tenia que atenderlos si o si, no importaba que yo no quisiera, por eso me fui. Era una mierda, perdón la palabra, pero es asi" (E105). "No, no tenemos derecho a decir que no, al menos que sea familiar, vecino o conocido, pariente, algún vinculo tiene que haber para que una diga que no. (E47). "Lo tengo que atender igual, sino en el burdel me echan...”.(E51)

Cuando arranqué a trabajar en la whiskería supuestamente podíamos elegir si atender o no a tal cliente, pero el día que no quise atender a un borracho, casi me echan. Nunca más rechacé atender a alguien por miedo a perder mi trabajo y no poder darle de comer a mis hermanos. (E188)

Como se puede observar, en muchos relatos emergen situaciones que evidencian modelos de relación de trabajo jerárquicos donde se recurre a la sanción (por ejemplo el despido) a quienes pretendan tener algún margen de libertad para negarse a atender determinados clientes.

El contraste con el trabajo más autónomo en la calle queda expresado en fragmentos como los siguientes:"Si sos libre como yo, hago lo que quiero; cuando trabajás para una madama, o lo hacés o lo hacés, ¿entendés?" (E54). "Es lo bueno de trabajar en la calle, si no quiero no lo atiendo y que se maneje. En los otros lugares los tenía que atender igual..." (E179)

Otros casos, referidos a locales cerrados muestran mayor flexibilidad: 
Lo podes evitar si querés, ojo, siempre y cuando no sean muy seguidos. Vos no podes estar eligiendo a todos, pero si en particular hay uno que vos no querés por determinado problema personal que tengas o algo, no ahí si bueno ta esta todo bien, obvio no pasa nada, son re flexibles en eso. $\mathrm{O}$ tienen olor no quiero que pasen, bueno ta no pasa nada inclusive, la encargada es la que se encarga de eso decirle eso: mira las chiquilinas no se quieren atender contigo porque tenés olor, se lo dicen. (E119)

Mientras tanto, el 9.6\% de la muestra expresa que siempre atiende a los clientes, esgrimiendo razones propias de ciertas normas sociales adscriptas a la profesión. En tal sentido, cierta ética profesional y mercantil les obliga a atender el cliente en la medida que pague por el servicio: "Digo, no podes estar eligiendo al cliente, yo a este no lo atiendo, atendélo vos, como despreciando a cliente y a las chiquilinas..." (E183). "Si yo no quisiera atender a un cliente, no me dedicaría a esto..." (E141)

\section{CONCLUSIONES}

De acuerdo a nuestro marco teórico, nos encontramos en una tercera fase de las políticas públicas referidas al fenómeno social de la prostitución. En esta fase, la principal división de aguas ocurre entre partidarios de aproximar el fenómeno de la prostitución a cualquier otra actividad mercantil lícita, y los partidarios de evitar la normalización de este fenómeno recurriendo, por ejemplo, a estrategias que pongan su acento en la demanda. En ambas posiciones hay importantes corrientes feministas que recreando el debate feminismo liberal vs. feminismo radical de décadas atrás, y partiendo de la complejidad de estas temáticas, fundamentan las diferentes posiciones, en algunos casos con ánimo dicotómico, en otros casos con el ánimo de llegar a cierta ética de mínimos. Es que como señala Gimeno, "en el seno del feminismo, cuestiones como los límites de la regulación del estado en materia de sexualidad, el derecho a decidir libremente sobre el propio cuerpo, la mercantilización del sexo y la dominación masculina, la victimización de las prostitutas y el reconocimiento de su agencia suscitan intensos debates que están lejos de ser zanjados” (GIMENO, 2013b: 3).

En este contexto de cambios, la figura delictiva del proxeneta se pone en tela de juicio. Reeditando las discusiones que dieron lugar a la Ley 8080 luego que la anterior Ley 5520 no reprimiera a quien regenteaba los prostíbulos, se elevan voces que sostienen la necesidad de liberalizar el mercado del sexo, permitiendo el lucro en los establecimientos y por esa vía asegurar además, ciertas condiciones mínimas a las trabajadoras sexuales. Como hemos visto, una solución de tal tipo presenta algunas críticas provenientes tanto de quienes provienen de posturas abolicionistas como de quienes defienden las posturas reglamentaristas pero con base en la denominada prostitución autónoma. Sin embargo, mientras la legislación no cambie, parece bastante evidente como se desprende de nuestra investigación, que existen figuras muy cercanas al proxenetismo, toda vez que aproximadamente la mitad de la muestra de mujeres en situación prostitucional del Uruguay expresa tener que cumplir un horario. Surge también de la evidencia manejada, que los patrones sancionan a las trabajadoras cuando 
llegan tarde o faltan a sus trabajos. Especialmente preocupante es el dato que arroja un $7 \%$ de personas prostituidas que no tiene ningún margen para negarse a atender a un cliente, lo que nos aleja del escenario de autonomía con el que cuenta el sistema reglamentarista del Uruguay para evitar caer en la trampa de la figura explotadora.

Respecto a cómo las trabajadoras sexuales se posicionan frente al fenómeno del proxenetismo, hemos advertido en este trabajo, una fuerte presencia de una particular mirada próxima a cierto individualismo metodológico. Desde este punto de vista, el proxenetismo es interpretado como algo que las trabajadoras sexuales podrían evitar si razonaran adecuadamente. Así se refieren por ejemplo, quienes nos responden señalando que "de ninguna manera aceptaría un proxeneta”, "yo soy muy lista para caer en eso” o “¿estás loco? Jamás permitiría que alguien se quede con lo que tanto me cuesta trabajar". Si bien estas expresiones pueden estar indicando una cierta conducta racional por parte de las trabajadoras y un margen de libertad que les permite comportarse de acuerdo a cómo piensan, lo cierto es que el proxenetismo también debe leerse como una expresión concreta del patriarcalismo y machismo predominantes que puede llevar a casos de dominación y sometimiento. Dicho de otra manera, se trata de un hecho sociocultural tan anclado en algunas de nuestras sociedades, que difícilmente puede llevarnos a pensar que se trata de un fenómeno finalmente librado a la voluntad de las partes. De hecho hemos visto en algunos relatos, cómo el proxenetismo deriva en situaciones de semi esclavitud y de evidente subordinación donde la víctima no tiene o no encuentra margen para librarse. Este problema es de fundamental importancia señalarlo, pues de su receptividad o no, podría depender la definición acerca de si el consentimiento es relevante o no a la hora de configura el delito.

\section{NOTAS DO AUTOR:}

1. Si bien algunos autores (Jimenez de Asúa, 1928; De Lora, 2007; Maqueda Abreu, 2009; Villacampa, 2012) prefieren clasificar en tres los modelos normativos (prohibicionismo, abolicionismo y regulacionismo), han surgido en los últimos años corrientes que encuentran en esta ya tradicional clasificación ciertas limitaciones, cuando se pretenden leer como categorías incompatibles. Al respecto, por ejemplo, Gimeno aboga por un "pacto de mínimos" entre regulacionistas y abolicionistas, "en los que ambos sectores del feminismo pudieran tener en común: lucha contra la trata, o reconocimiento de derechos humanos a las mujeres que se dedican a la prostitución" (GIMENO, 2013:1).

2. La posición de Luisi, fue implementada el 27 de Abril de 1932, al derogarse la reglamentación de la Ley de 1928, aunque por un período de solo de tres meses, al dictarse una nueva reglamentación en Julio de 1932 (Albanell, 1932: 25-26). 
3. Actualmente se encuentra en estudio del Parlamento una Reforma del Código Penal que incluye una redacción del delito de proxenetismo afín a esta tendencia. Dice la propuesta sobre proxenetismo: "Toda persona que explote la prostitución de otra mediante engaño, violencia, amenaza o cualquier otro medio de intimidación o coerción, con ánimo de lucro, será castigada con una pena de dos a ocho años de penitenciaría" (Uruguay, 2004). Nótese cómo la figura delictiva no aplicaría en caso de consentimiento.

4. Bajo esta interpretación también se ha discutido si acaso no configura delito de proxenetismo quien alquila un bien inmueble para ser utilizado como prostíbulo. Los propios legisladores analizaron ese posible escenario previo a legislar en 1927 e incorporaron una solución en su Decreto Reglamentario. Más en la actualidad, ha sido muy comentado el caso del reconocido Dr. Zaffaroni (Juez de la Suprema Corte de Justicia de Argentina) denunciado por la ONG La Alameda en 2012 por alquilar seis de sus propiedades como prostíbulos. El Dr. Zaffaroni adujo desconocer que en dichos apartamentos se ejerciera la prostitución.

\title{
NOTAS METODOLÓGICAS:
}

1. la letra E seguida de un número entre paréntesis al final de una frase, refiere al número de entrevista.

2. Las frases en cursiva son copia textual de las entrevistadas realizadas en nuestro trabajo de campo

3. Decimos cantidad de horas y no franja horaria, pues en algunas zonas particulares se suele pactar el horario en la que trabajará cada una; por ejemplo mañana, tarde o noche.

\section{THE PROCUREMENT CRIME TRENDS UNDER THE REGULATIONS ON SEX WORK. A SOCIO LEGAL ANALYSIS FROM THE VISION AND OPINION OF URUGUAYAN WOMEN IN SITUATION OF PROSTITUTION}

\begin{abstract}
In this article we will explore how the social awareness of the offense of procurement has been configured and the way it has been changing according to the paradigm of the interpretation of the prostitution phenomenon with which we look at this offense. Based on the current situation in Uruguay, where sex work is regulated, we will support from a legal sociological perspective that procurement as an offense is going through an interpretative phase of transition, given the difficulties of applying the norm in the present context. Based on empirical evidence resulting from a field research of 188 female sex workers, we advise about the connection that might exist between the relationship of dependency and the offense of procurement.
\end{abstract}

Keywords: prostitution, sex work, procurement, gender, criminal law 


\section{BIBLIOGRAFÍA}

ALBANELL, EDUARDO (1932). Legislación sobre proxenetismo y delitos afines, Montevideo, Facultad de Derecho y Ciencias Sociales.

CHTS (2014). Anteproyecto de Ley Trabajo Sexual, Montevideo, inédito.

DE LORA, PABLO (2007). ¿Hacernos los suecos? La prostitución y los límites del Estado, en DOXA, Cuadernos de Filosofía del Derecho, 30 (2007), pp. 451-470

EKBERG, GUNNINA (2004). Sobre la Ley Sueca que prohíbe la compra de servicios sexuales (en línea) Observatorio Violencia, en www.observatorioviolencia.org/.../DOC1164006147_informeleysueca (Recuperado $4 / 12 / 2014)$

GELSTHORPE, LORAINE et alt (2004). Sexuality Repositioned: Diversity and the Law, Hart Publishing, USA\&Canada.

GIMENO, BEATRIZ (2013). La prostitución: ¡abolir o legislar? Un giro en el debate (en línea) Feminicidio.net, en http://www.feminicidio.net/documento/art\%C3\%ADculos-sobre-prostituci\%C3\%B3n-de-beatriz-gimenoactivista-feminista-y-lgtb (Recuperado 10/3/2015)

(2013b). Los límites de la regulación (en línea) Feminicidionet, en http://www.feminicidio.net/documento/art\%C3\%ADculos-sobre-prostituci\%C3\%B3n-de-beatriz-gimenoactivista-feminista-y-lgtb (Recuperado 10/3/2015)

JIMÉNEZ DE ASÚA, L., (1928). Libertad de amar y derecho a morir, Madrid: Historia Nueva (1950). Tratado de Derecho Penal, Vol. 1, Madrid, Losada.

JORDAN, ANN (2012). La ley sueca de penalización de los clientes: un experimento fracasado de ingeniería social (en línea) en https://elestantedelaciti.wordpress.com/2012/04/25/la-ley-sueca-depenalizacion-de-los-clientes-un-experimento-fracasado-de-ingenieria-social/ (Recuperado 4/12/2014).

LAZO, GEMMA (2011). Los orígenes del delito de proxenetismo en los códigos penales españoles, en Fernando Pérez Álvarez (ed), Temas actuales de investigación en ciencias penales, Salamanca, Universidad de Salamanca, pp. 327-347.

MAQUEDA ABREU (2009). Prostitución, feminismos y Derecho penal, Granada, Ed. Comares.

MILUSKA VIDA Y DIGNIDAD (2006). Trabajo sexual y prostitución desde la mirada de las trabajadoras sexuales organizadas (en línea) Boletín Rostro de Mujer, en www.cepesju.org/mat_new/boletines_revis/boletin_rm_portugl.pdf(consultado 23/10/2014).

NACIONES UNIDAS (1949). Convención para la represión de la Trata De Personas y de la explotación de la prostitución ajena (en línea) Naciones Unidas, en http://daccess-ods.un.org/TMP/1049474.77579117.html (Recuperado 9/12/2014)

TROCHÓN, YVETTE (2006). Las rutas de Eros. La trata de blancas en el Atlántico Sur. Argentina, Brasil y Uruguay (1880-1932), Montevideo, Taurus. 
REAL ACADEMIA ESPAÑOLA (2001) Diccionario de la Real Academia Española (en línea) RAE. En http://www.rae.es/recursos/diccionarios/drae (Recuperado16/9/2014)

REGERINGSKANSLIET (2004). Prostitución y Tráfico de Mujeres (en línea) en webs.uvigo.es/pmayobre/textos/varios/prostitucion_suecia.pdf(recuperado 4/12/2014)

SCOTT, JOAN (1996). El género: una categoría útil para el análisis histórico, en Lamas Marta (Comp) El género: la construcción cultural de la diferencia sexual. PUEG, México, 2006, p. 265-302.

SOCIEDAD DE NACIONES (1910). Convenio internacional para la supresión del tráfico de trata de Blancas, firmado en parís el 4 de mayo de 1910, enmendado por el Protocolo firmado en lake success, nueva york, el 4 de mayo de 1949 (en línea), en https://www.scjn.gob.mx/libro/InstrumentosConvenio/PAG1065.pdf (Recuperado 9/12/2014).

URUGUAY (1927). Ley $\mathbf{8 0 8 0}$ (en línea) Poder Legislativo, en http://www.parlamento.gub.uy/leyes/AccesoTextoLey.asp?Ley=8080.\&Anchor= (Recuperado 11/12/2014) (1995).
Ley
16707
(en línea)
Poder
Legislativo,
en

http://www.parlamento.gub.uy/leyes/AccesoTextoLey.asp?Ley=16707\&Anchor= $($ Recuperado 11/12/2014) (2002). Ley 17515 (en línea) Poder Legislativo, en http://www.parlamento.gub.uy/leyes/AccesoTextoLey.asp?Ley=17515\&Anchor= $($ Recuperado 11/12/2014) (2002). Ley 17515 (en línea) Poder Legislativo, en http://www.parlamento.gub.uy/leyes/AccesoTextoLey.asp?Ley=17515\&Anchor= (Recuperado 11/12/2014) $\begin{array}{cccc}\text { (2004). Repartido N. 1545, Comisión de Constitución, Códigos, Legislación General y Administración } \\ \text { (en } & \text { línea) } & \text { Poder } & \text { Legislativo, }\end{array}$ http://www.parlamento.gub.uy/repartidos/AccesoRepartidos.asp?Url=/repartidos/camara/d200401154500.htm

VILLACAMPA, CAROLINA (2012). Políticas de criminalización de la prostitución: análisis crítico de su fundamentación y resultados, en UNED. Revista de Derecho Penal y Criminología, 3.a Época, n.o 7, pp 81 - 142.

Trabalho enviado em 11 de dezembro de 2014.

Aceito em 13 de março de 2015. 